\title{
Experience of Packaging and Design of Domestic Animation Peripheral Products
}

\author{
Bin Yang \\ Tianjin Light Industry Vocational Technicaal College, 300192
}

Keywords: Domestic animation; peripheral products; problems; packaging design

\begin{abstract}
In the 1990s, China experienced the golden age of domestic animation. With the implementation of China's opening-up policy, the influx of foreign cartoons into the Chinese market and occupied the dominance of the animation market, the domestic animation industry chain is not perfect, the animation peripheral product development Serious shortage, leading to $80 \%$ of the domestic animation market profits are flowing abroad. This paper aims to provide a reference for the development of animation products and animation products in China by analyzing the types of animation products and the problems in the packaging and design of the surrounding animation products.

With the continuous improvement of the market economy system, animation gradually from a literary form to the industrialization and commercial direction, but the development of animation industry needs a complete industrial chain as a support, and to have a sound marketing model. Throughout the world of animation industry chain, $70 \%$ to $80 \%$ of the profits by the surrounding products to achieve. But the domestic animation has works without product, product and no product of the status quo an effective breakthrough, leading to the slow development of Chinese animation, China should actively learn from Japan, the United States and other cartoon animation marketing strategy, and actively tap and expand our potential animation market capacity. The article analyzes the problems existing in the packaging of the domestic animation, discusses how to improve the packaging and design efficiency of the domestic animation peripheral products, and capture the animation market.
\end{abstract}

\section{An Overview of Animation Peripheral Products}

Anime peripheral products refers to the animation as the carrier, the surrounding potential resources for mining, is a comic, an extension of animation, but also an extension of cartoons, animation culture. Mainly including animation features clothing, toys, decorations, music, books, etc., the success of the commercial value of the long history of animation works, for example, Disney in various countries around the world have opened Disneyland, the classic Mickey Mouse, Donald Duck and other roles as Disney theme, a wide range of products, the value of the benefits obtained is immeasurable. Common animation peripheral product categories are mainly based on the use of the product is divided into two categories: first, is the toy products, for example, GK model, SD doll, building blocks, food, etc. [1]. Second, the implementation of the use of the value of daily necessities, such as clothing, stationery, food, books, mobile phone accessories.

\section{Domestic Animation Peripheral Product Packaging and Design Problems}

2.1 Policy Issues. Animation industry in the early development did not get the government's attention, leading to many of our excellent animation works did not derive the peripheral products. With the development of animation industry, as well as animation products around the profits, the Government began to attach importance to the management of animation industry began to attach importance. But China's large animation production base, most of the production of foreign animation products, leading to the competitiveness of domestic animation is weak, the surrounding product development space is smaller. Get the development of animation products is mainly for children, the breadth of the market by a certain degree of obstacles. Second, China's animation industry to play a management function of the department too much, for example, SARFT, Ministry of Culture, Ministry of Education, resulting in policy deployment on the contradictions and conflicts on the operation of the animation industry had a negative impact. 
2.2 Domestic Animation Industry Chain is not Mature. Most of our animation production enterprises do not have animation products production plan, so many animation film and television institutions did not set up the marketing department, the Department of the Ministry of animation and product development. Many animation film and television institutions wait until the animation sought after hastily contact manufacturers to produce peripheral products, it is difficult to ensure that animation, design and animation derivative production synchronization, to a certain extent, wasted the influence of the cartoon image [2]. For example, at the beginning of this century, China's CCTV broadcast "the legend", "the sky fell a pig" and other domestic animation, get a good response, but in addition to some animation books, and did not develop other peripheral products, The market influence of these anime works.

2.3 Domestic Animation Propaganda is not Enough. First of all, China's lack of animation has the appeal of the image of the star, from the number of animation production to accumulate a number of cartoon images, but more than $50 \%$ of the other countries to do "processing" products, the lack of local characteristics of China Anime [3]. Second, although there will be some animation boutique come out, but not enough propaganda, resulting in falling into the unknown situation, the scope of its own animation to be limited, its peripheral products is no development space.

2.4 Piracy Problems are Difficult to Contain. In recent years, "Pleasant Goat and Big Wolf" and "Bear" have become the most successful case of domestic animation industry, industrial chain has been extended to books, audio and video, toys, stationery and other industries, there is a huge market efficiency and economic interests, But the market piracy products gradually flooded, resulting in the production of manufacturers difficult, creative costs can not be recycled, leading to the loss of animation and other vicious circle of creative talent.

\section{Cartoon Peripheral Products Packaging and Design}

3.1 Seize the Characteristics of Consumer Groups Around the Domestic Animation. At this stage I am the main consumer of the main consumer market is adolescents, can be divided into 3-12 year old age groups, 12-22 year old student groups and 22 years of age or more animation enthusiasts. At the same time all age groups of consumer groups have different consumption standards. So the animation around the design of the product when the needs of the age groups for the needs of the characteristics of consumer groups around the design of animation products. For example, in the low-end animation products are mainly aimed at 3-12-year-old low-age groups, high-end technical animation products are mainly for more than 22 years of animation enthusiasts. At the same time in the animation product design process, but also has a different standard, for example, animation enthusiasts pay more attention to the role of the reduction of the role of animation, quality, beauty and so on.

3.2 Reasonable Choice of Animation Design Products Around the Packaging Type. First, upright type. This type of animation products focus on the characteristics of the animation and the world view of the direct display, usually with a ratio of 1: 1 reduction, the characters in the characters. The main product development direction is a large toy, hand model. This type of animation products pay more attention to the degree of rejuvenation and design, as well as a fixed audience, is the core of the creation of animation brand. Second, the public type. This product type is more focused on the practicality of the product, its production and development can be divided into three types according to the degree of difficulty: 1. Product selection, this part of the design is less difficult, visual appearance is obvious, usually directly Product surface affixed or printed on the animation logo, too many similar products, the development of the animation brand has no substantive effect. 2. Two-dimensional animation character design, the product and animation works closely, the cost is not high, the audience accepted a wide range of consumers prone to a relatively strong desire to buy. 3. Three-dimensional cartoon image design, product design form, style, color and other image consistent with the animation, animation and animation will be fully integrated, the formation and development of the brand have a crucial impact [4]. Third, personality type. Using a unique perspective on the animation image of the interpretation and innovation, reflecting the individual characteristics of animation products. China's domestic animation industry 
development should be a reasonable choice of animation products around the design type, the maximum extent to meet consumer demand for product diversification.

3.3 Strengthen the Image of Animation, Enhance the Appeal of Animation Products. Animation product developers to carry out an in-depth analysis of the cartoon image, refining the characteristics of the role of the animation and the world view, as far as possible in the product will be animated characters vivid, delicate and complete performance, the greatest degree of close to the original role of animation, Fans of the product purchase desire. For example, now more and more popular COSPLAY wind, and the high degree of reduction of hand-made model, the value of animation image has been greatly improved. Second, the animation works are in the context of a specific story, the animation around the product development can be on the characters in the animation appears in a particular scene to reproduce the original story, or products and packaging to form interesting comic effects, Enhance the attractiveness of animation products.

3.4 Three-dimensional Product Packaging. First of all, to highlight the advantages of animation product packaging shape, jumping the inherent image of the packaging, the use of brand effect introduced novel appearance of the animation peripheral products. Second, the packaging of peripheral products to highlight the modern market is highly concerned about the concept of environmental protection, for example, the use of recyclable materials for product packaging, not only can reduce environmental pollution can reduce packaging costs. Finally, to highlight the cultural value of product packaging, and local market customs, human and other contact, for example, Shanghai Disneyland, in traditional Chinese to join, to Mickey and other animated image to wear Tang suit, to attract the attention of the Chinese people, Own brand benefits.

\section{Summary}

In summary, the development of the animation industry needs to have a complete industrial chain as a support, and to have a sound marketing model, the domestic animation peripheral product packaging and design to break through a variety of limitations, as well as works without products, Product without product status quo. To seize the characteristics of consumer groups around the domestic animation products, a reasonable choice of animation products around the design type, strengthen the animation image to enhance the attractiveness of animation products, and actively tap the expansion of China's potential animation market capacity, enhance the attractiveness of animation products, The rapid development of domestic animation industry, and to create greater economic benefits of the animation industry.

\section{Reference}

[1] Ding Xiang. Thoughts on the design and development of animation peripheral products Comment on "Product Design and Development (3rd Edition) (translated version)" [J]. News and Writing, 2016 (10).

[2] Zhang Xiaobo, Liu Chao. Discussion on the importance of brand image in the packaging design of animation peripheral products [J].

[3] Yao Juan. The role of brand image in the packaging design of animation products [J]. Art Technology, 2015 (10).

[4] Li Wen. Anime character in its peripheral products in the secondary design - to hand mold crafts as an example [J]. Art Technology, 2014 (10). 